\title{
Construction of Nonsinusoidal Oscillation Waveform Function and Technological Parameters for Continuous Casting Mold
}

\author{
Chao Zhou $\mathbb{D}^{1,2}$ Xingzhong Zhang $\mathbb{D}^{2},{ }^{2}$ Fang Wang $\mathbb{D}^{3},{ }^{3}$ and Subo Ren ${ }^{2}$ \\ ${ }^{1}$ Ocean College, Hebei Agricultural University, Qinhuangdao 066003, China \\ ${ }^{2}$ National Engineering Research Center for Equipment and Technology of Cold Strip Rolling, Yanshan University, \\ Qinhuangdao 066004, China \\ ${ }^{3}$ School of Science, Yanshan University, Qinhuangdao 066004, China \\ Correspondence should be addressed to Xingzhong Zhang; zhangxzh@ysu.edu.cn and Fang Wang; wangfang@ysu.edu.cn
}

Received 8 October 2019; Accepted 5 December 2019; Published 31 March 2020

Academic Editor: Carlos Aguilar-Ibanez

Copyright (C) 2020 Chao Zhou et al. This is an open access article distributed under the Creative Commons Attribution License, which permits unrestricted use, distribution, and reproduction in any medium, provided the original work is properly cited.

\begin{abstract}
Nonsinusoidal oscillation techniques can shorten the negative strip time and improve the slab surface quality in the process of steel continuous casting. But the acceleration of nonsinusoidal oscillation is higher than that of the sinusoidal oscillation. So it is easy to result in the impact for the mold movement. To solve this problem, a nonsinusoidal oscillation waveform function of mold was constructed, which had good dynamic characteristics. And the smaller acceleration can reduce the impact of the oscillator. By analyzing the parameters of oscillation technology, the calculation method of each oscillation technological parameter for seven section functions was presented and the multitechnological parameter curves were given. Based on the technological parameters of sinusoidal oscillation, a synchronous control model of nonsinusoidal oscillation was determined. The results show that the parameters can satisfy the limit value in theory, which can enhance the casting speed, surface quality of slab, and provide reference for further practice in industry.
\end{abstract}

\section{Introduction}

Mold oscillation plays an important role in continuous casting. It decides whether the continuous casting progress is smooth or not. The velocity rules of mold oscillation went through rectangular, trapezoid, sinusoidal, and nonsinusoidal oscillation. With the demand growing for the surface quality and casting speed of slab, nonsinusoidal oscillation has been one of the key technologies to realize highly efficient continuous casting [1-4].

Nowadays, mold oscillation technologies used in production mainly include sinusoidal and nonsinusoidal oscillations. Sinusoidal oscillation could reduce negative strip time and improve surface quality of slab when high frequency and small amplitude operation are adopted $[5,6]$. Lin et al. [7] optimized the sinusoidal oscillation parameters for Nanjing steel, the lubrication between the mold and slab had been improved, the demoulding resistance was reduced, the hook-type oscillation mark was eliminated, and the slab quality was enhanced. Wang et al. [8] found that the hooktype oscillation marks of slabs could be reduced significantly by increasing frequency and reducing amplitude. Although sinusoidal oscillation can reduce negative strip time, the positive strip time also reduces. In contrast, at the time of reducing negative strip time for nonsinusoidal oscillation, positive strip time can be prolonged which is useful for mold powder consuming. Nonsinusoidal oscillation can obtain reasonable technological parameters and is an ideal oscillation mode for mold [9]. The research of nonsinusoidal oscillation is mainly focused on oscillation waveform, realization way, and parameter control. The waveform functions of nonsinusoidal oscillation mainly contain entire function and piecewise function. An oscillation waveform of entire function was developed by Suzuki et al. [10], which had been used in many iron and steel enterprises. The principle of nonsinusoidal oscillation was studied by means of the rotation vector method, and $\mathrm{Li}$ et al. proposed an oscillation waveform which could be realized by using a 
couple of elliptical gears [11], which had been applied in many companies and achieved good results. Zhang et al. $[12,13]$ proposed a nonsinusoidal oscillation waveform composed of two sinusoidal functions, which could be realized by double eccentric shafts. Liu et al. presented the entire function of nonsinusoidal oscillation waveform which could be realized by noncircular gears [14]. Hong et al. [15] proposed an oscillation waveform function composed of Fourier series. Although the entire function is easy to be constructed, the values of basic parameters have a certain limit. An oscillation waveform function consisting of three sections of sine trigonometric functions was proposed. The displacement and velocity curves are continuous, but the acceleration curves are discontinuous. For this oscillation waveform function, the oscillator would not move smoothly and vibratory shock should occur [16]. Meng and Zhu [17] and $\mathrm{Li}$ et al. [18] constructed a nonsinusoidal oscillation waveform of piecewise function. The displacement, velocity, and acceleration curves are continuous. However, the maximum acceleration is larger and it has bigger impact for the oscillator when the mold is at the uppermost point and lowest point. Then, an oscillation waveform function was proposed in this paper, which has lower maximum acceleration and good dynamic characteristic.

Compared with sinusoidal oscillation, nonsinusoidal oscillation has the advantages of shorter negative strip time, longer positive strip time, smaller positive strip velocity, and larger negative strip distance. However, the acceleration and inertia force of nonsinusoidal oscillation are larger, which will result in the impact and make against to the normal operation of oscillator. The inertia force of nonsinusoidal oscillation is mainly decided by waveform function. In order to obtain better dynamic characteristic of oscillation waveform, a nonsinusoidal oscillation waveform composed of seven section functions was proposed, which had lower acceleration and inertia force. Based on nonsinusoidal oscillation waveform of seven section functions, the calculation methods of technological parameters were given, the multitechnological parameter curve was obtained, and the synchronous control model of casting speed and oscillation frequency was determined. The calculation results indicate that the oscillation waveform function proposed in this paper will be useful to further improve the quality of slab and highly efficient continuous casting.

\section{Construction of Nonsinusoidal Oscillation Waveform}

The lower acceleration for oscillator results in smaller inertia force. The velocity function of nonsinusoidal oscillation waveform is constructed, which is composed of seven sections, shown in Figure 1. From Figure 1, it can be seen that $A B, C D, F G$, and $H$ Kare straight lines and $B C, D E F$, and $G H$ are parabolas. The functions of oscillation waveform are as follows.

The velocity function is

$$
v= \begin{cases}v_{B}, & 0 \leq t \leq t_{B}, \\ -k\left(t-t_{B}\right)^{2}+v_{B}, & t_{B} \leq t \leq t_{C}, \\ -2 k\left(t_{C}-t_{B}\right)\left(t-t_{C}\right), & t_{C} \leq t \leq t_{D}, \\ k\left(t-\frac{1}{2 f}\right)^{2}-v_{B}-2 k\left(t_{C}-t_{B}\right)\left(\frac{1}{2 f}+t_{B}-2 t_{C}\right), & t_{D} \leq t \leq t_{F}, \\ 2 k\left(t_{C}-t_{B}\right)\left(t+t_{C}-\frac{1}{f}\right), & t_{F} \leq t \leq t_{G}, \\ -k\left(t+t_{B}-\frac{1}{f}\right)^{2}+v_{B}, & t_{G} \leq t \leq t_{H}, \\ v_{B}, & t_{H} \leq t \leq t_{K},\end{cases}
$$

where $v$ is the velocity of mold, $\mathrm{mm} / \mathrm{s}, h$ is the oscillation amplitude, mm, $f$ is the oscillation frequency, $\mathrm{Hz}$, and $\alpha$ is the waveform modification ratio of nonsinusoidal oscillation. $t_{C}, t_{D}, t_{F}$, and $t_{G}$ are the time periods of different positions for mold, $s, v_{B}$ is the velocity of point $B$, $t_{F}=(1 / f)-t_{D}, t_{G}=(1 / f)-t_{C}$, and $t_{H}=(1 / f)-t_{B}, v_{B}$ $=k\left(t_{C}-t_{B}\right)^{2}, \quad k=(3 h) /\left[3 t_{C}\left(t_{C}-t_{B}\right)^{2}-\left(t_{C}-t_{B}\right)^{3}\right], \quad t_{B}=$ $\alpha /[f(1+\alpha)], t_{C}=(1+\alpha) /(4 f)$, and $t_{D}=1 /(2 f)+t_{B}-t_{C}$. 
The displacement function is

$$
s= \begin{cases}v_{B} t, & 0 \leq t \leq t_{B}, \\ -\frac{k}{3}\left(t-t_{B}\right)^{3}+v_{B} t, & t_{B} \leq t \leq t_{C}, \\ -k\left(t_{C}-t_{B}\right)\left(t-t_{C}\right)^{2}+c_{1}, & t_{C} \leq t \leq t_{D}, \\ \frac{k}{3}\left(t-\frac{1}{2 f}\right)^{3}-v_{B} t-2 k t\left(t_{C}-t_{B}\right)\left(\frac{1}{2 f}+t_{B}-2 t_{C}\right)+c_{2}, & t_{D} \leq t \leq t_{F}, \\ k\left(t_{C}-t_{B}\right)\left[t-\left(\frac{1}{f}-t_{C}\right)^{2}\right]+c_{3}, & \\ k\left[t-\left(\frac{1}{f}-t_{B}\right)\right]^{3}+v_{B} t+c_{4}, & t_{F} \leq t \leq t_{G}, \\ -\frac{1}{3}\left[t-\frac{1}{f}\right), & t_{G} \leq t \leq t_{H}, \\ v_{B}\left(t-t_{K},\right.\end{cases}
$$

where $s$ is the displacement of mold, $\mathrm{mm}$, $c_{1}=v_{B} t_{C}-(k / 3)\left(t_{C}-t_{B}\right)^{3}=\left(v_{B} / 3\right)\left(t_{B}+2 t_{C}\right)$, $c_{2}=\left(v_{B} / 2 f\right)+(k / f)\left(t_{C}-t_{B}\right)\left((1 / 2 f)+t_{B}-2 t_{C}\right)$, $c_{3}=-\left(v_{B} / 3\right)\left(t_{B}+2 t_{C}\right)$, and $c_{4}=-\left(v_{B} / f\right)$.

The acceleration function is

$$
a= \begin{cases}0, & 0 \leq t \leq t_{B}, \\ -2 k\left(t-t_{B}\right), & t_{B} \leq t \leq t_{C}, \\ -2 k\left(t_{C}-t_{B}\right), & t_{C} \leq t \leq t_{D}, \\ 2 k\left(t-\frac{1}{2 f}\right), & t_{D} \leq t \leq t_{F}, \\ 2 k\left(t_{C}-t_{B}\right), & t_{F} \leq t \leq t_{G}, \\ -2 k\left(t+t_{B}-\frac{1}{f}\right), & t_{G} \leq t \leq t_{H}, \\ 0, & t_{H} \leq t \leq t_{K},\end{cases}
$$

where $a$ is the acceleration, $\mathrm{mm} / \mathrm{s}^{2}$.

When $h$ equals $4 \mathrm{~mm}$ and $f$ equals $2 \mathrm{~Hz}$, the oscillation waveform curves are shown in Figure 2 with different waveform modification ratios. From Figure 2, it can be found that the velocity curve is smooth and continuous. So there will be no rigid vibration impact occurring. The acceleration curve is continuous without the value sudden change. Thus, there will be no flexible vibration impact occurred. The maximum acceleration is lower compared with oscillation waveform of five sections with the same basic parameters, shown in Figure 3. Then, the inertia force is smaller. In brief, the oscillation waveform has good dynamic characteristics.

\section{Technological Parameters and Synchronous Control Model}

Technological parameters decide the production of continuous caster and the surface quality of slab, so it is necessary to analysis them.

3.1. Negative Strip Time Curves. Negative strip time is the period time that the velocity of mold moving downward is faster than casting speed shown in Figure 4. If the negative strip time is longer, the oscillation mark will be deeper:

$$
t_{N}=2\left(\frac{1}{2 f}-t_{1}\right) \text {. }
$$

For processing,

$$
t_{1}=\frac{1}{2}\left(\frac{1}{f}-t_{N}\right) .
$$

The velocity of mold is $v_{c}$ at time $t_{1}$. Submitting equation (5) into equation (1) (the third equation),

$$
t_{N}=\frac{1-\alpha}{2 f}-\frac{v_{c}(1-\alpha)^{2}\left(\alpha^{2}+4 \alpha+1\right)}{24 h f^{2}(\alpha+1)^{2}},
$$

where $t_{N}$ is the negative strip time, $s$, and $v_{c}$ is the casting speed, $\mathrm{mm} / \mathrm{s}$.

If $Z=(2 h / E)(\mathrm{mm} \cdot \mathrm{min} / \mathrm{m})$ and $E=\left(v_{c} / 1000\right) \times 60$, the relationship between $t_{N}$ and $Z$ is obtained as 


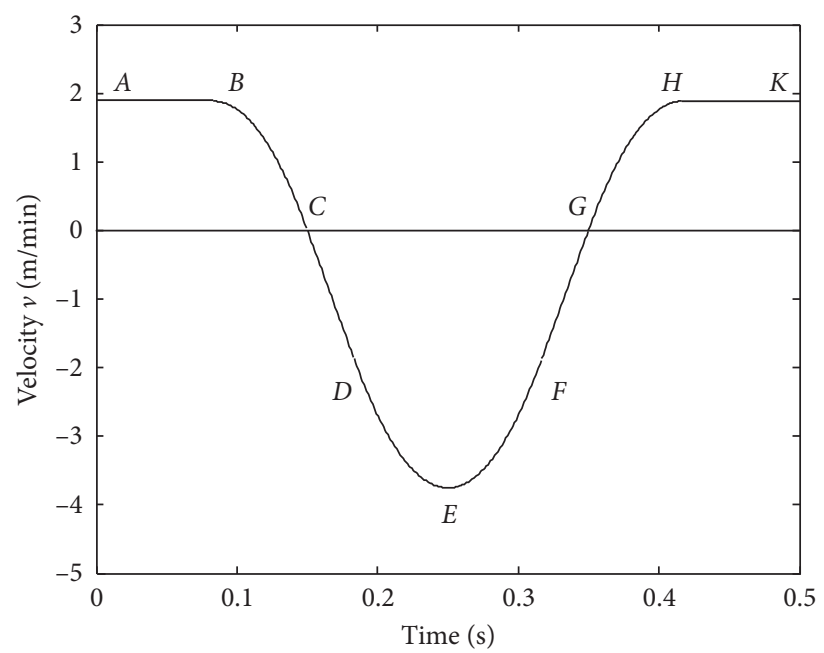

FIGURE 1: Sketch of velocity curve for nonsinusoidal oscillation.

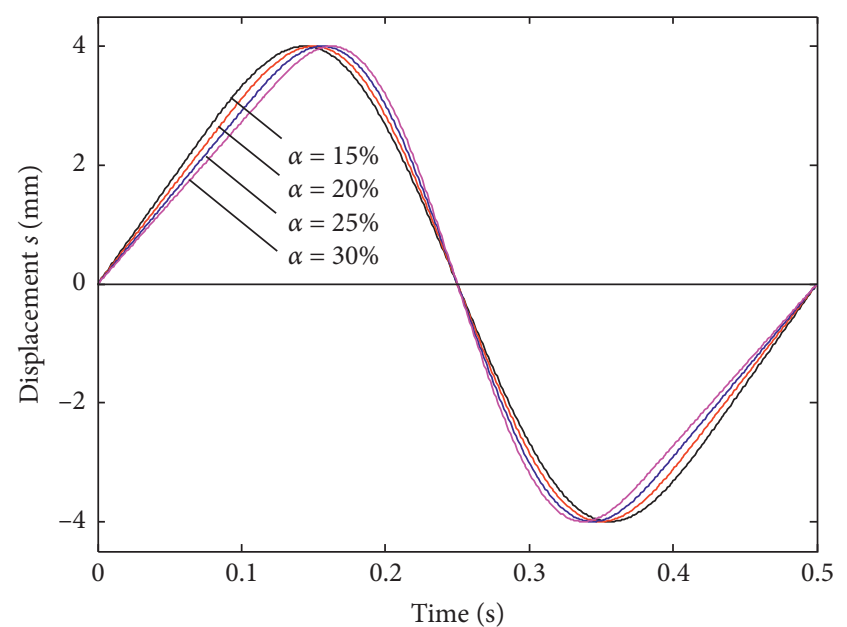

(a)

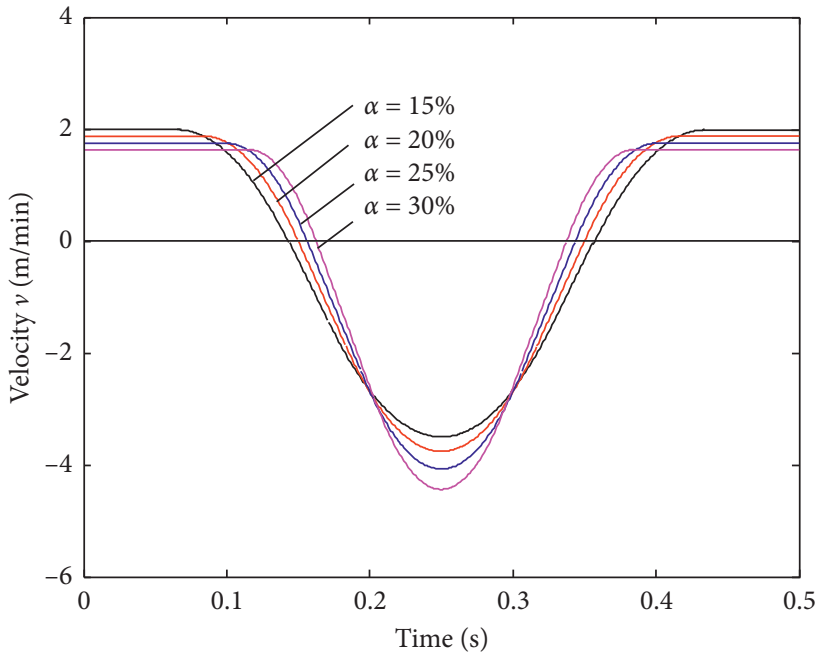

(b)

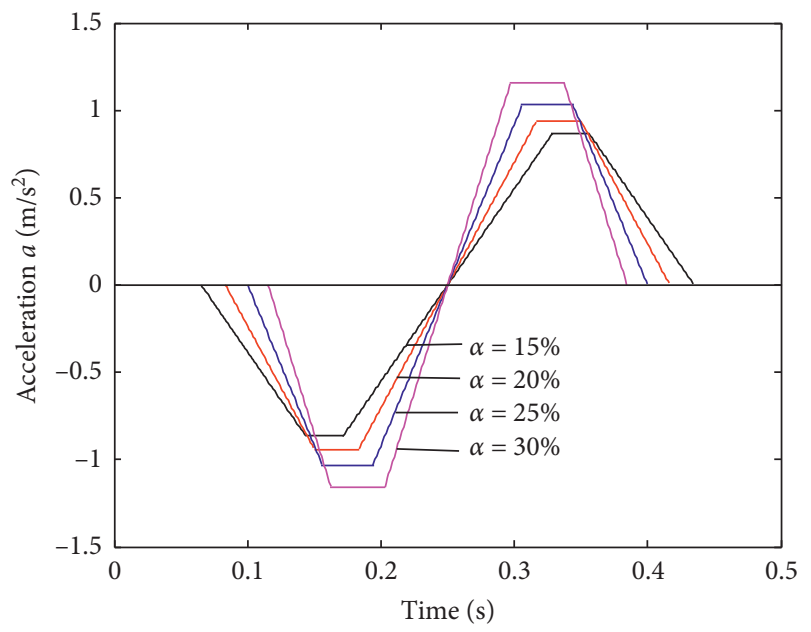

(c)

Figure 2: Nonsinusoidal oscillation waveform of seven section functions. (a) Displacement curves. (b) Velocity curves. (c) Acceleration curves. 


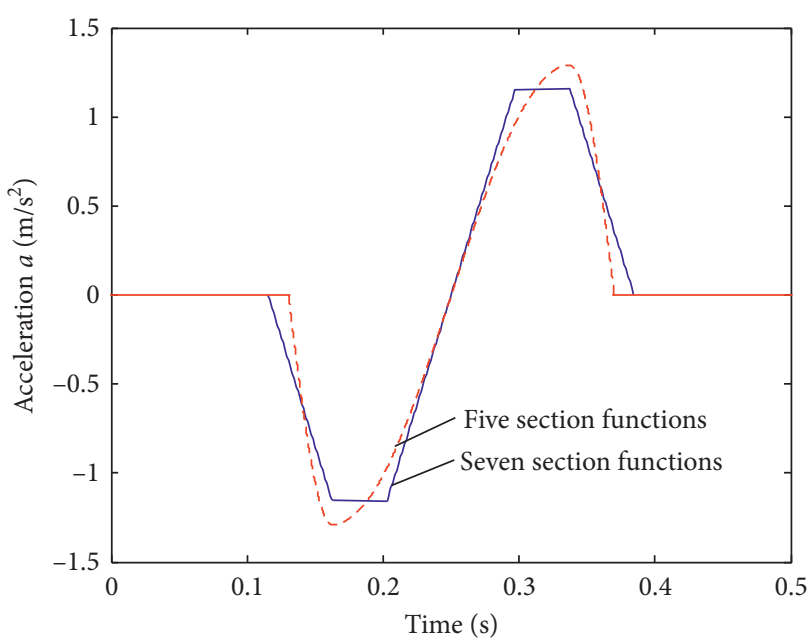

Figure 3: Acceleration curves with $h=4 \mathrm{~mm}, f=2 \mathrm{~Hz}$, and $\alpha=30 \%$.

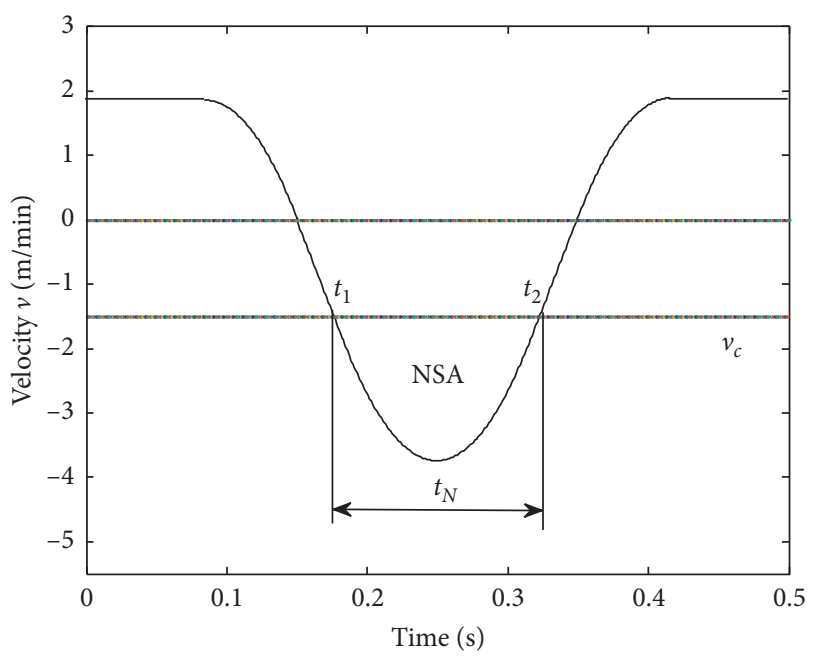

FIGURE 4: Velocity curve for mold oscillation.

$$
t_{N}=\frac{1-\alpha}{2 f}-\frac{25(1-\alpha)^{2}\left(\alpha^{2}+4 \alpha+1\right)}{18 Z f^{2}(\alpha+1)^{2}},
$$

when $\alpha$ equals $20 \%$ and $Z$ equals different values; negative strip time curves are shown in Figure 5.

3.2. Negative Strip Ratio. Negative strip ratio is defined as

$$
\mathrm{NS}=1-\frac{4 f h}{(1-\alpha) v_{c}} .
$$

The larger negative strip ratio is helpful for removing the slab from the mold. Submitting (8) into equation (6), the relationship between $t_{N}$ and NS can be expressed as

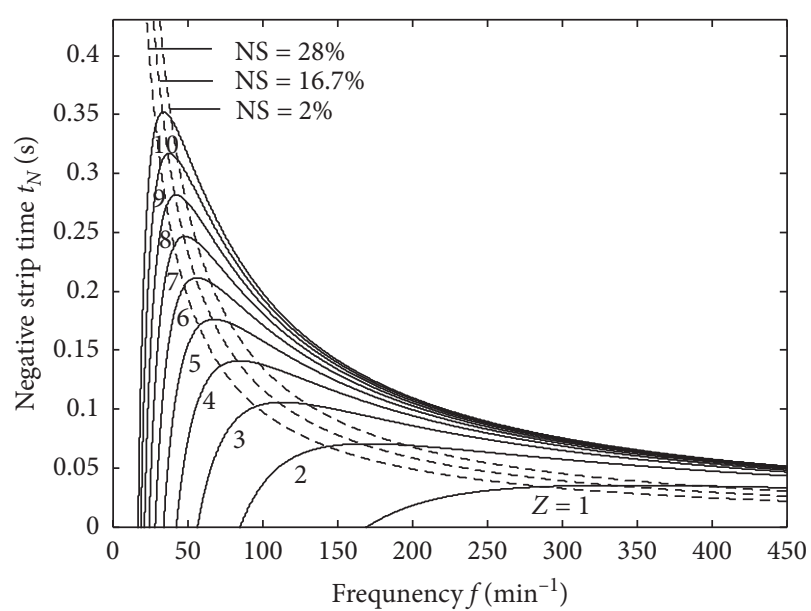

FIgURE 5: Negative strip time curves.

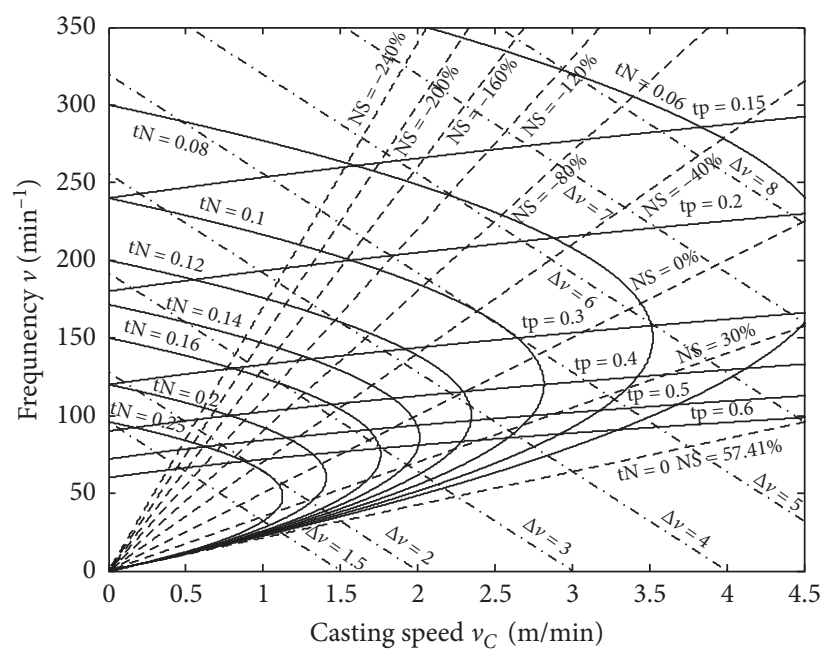

FIGURE 6: Multiparameter curves of nonsinusoidal oscillation with $\alpha=20 \%$ and $h=4 \mathrm{~mm}$.

$$
t_{N}=\frac{1-\alpha}{2 f}-\frac{(1-\alpha)\left(\alpha^{2}+4 \alpha+1\right)}{6 f(\alpha+1)^{2}(1-N S)} .
$$

When $\alpha$ equals $20 \%$, NS equals different values, and the change of $t_{N}$ with $f$ is shown in Figure 5.

3.3. Negative Strip Time Ratio. Negative strip time ratio is the ratio between negative strip time and half an oscillation period:

$$
\mathrm{NSR}=\frac{t_{N}}{0.5 T}=2 f t_{N}=1-\alpha-\frac{v_{c}(\alpha-1)^{2}\left(\alpha^{2}+4 \alpha+1\right)}{12 h f(\alpha+1)^{2}},
$$

where NSR is the negative strip time ratio, \%. 
TABLE 1: Caster parameters.

\begin{tabular}{lcc}
\hline Item & Unit & Value \\
\hline Slab section size & $\mathrm{mm} \times \mathrm{mm}$ & $180 \times 1800$ \\
Amplitude & $\mathrm{mm}$ & \pm 4 \\
Frequency & $\mathrm{min}^{-1}$ & 104 \\
Casting speed & $\mathrm{m} / \mathrm{min}$ & 1.15 \\
\hline
\end{tabular}

TABLE 2: Technological parameters of nonsinusoidal oscillation.

\begin{tabular}{|c|c|c|c|c|c|c|c|}
\hline$v_{c}(\mathrm{~m} / \mathrm{min})$ & $f\left(\min ^{-1}\right)$ & $t_{N}(\mathrm{~s})$ & NS (\%) & NSA $(\mathrm{mm})$ & NSR (\%) & $t_{p}(\mathrm{~s})$ & $\Delta v(\mathrm{~m} / \mathrm{min})$ \\
\hline 0.3 & 60 & 0.357 & -300 & 6.107 & 71.48 & 0.643 & 1.239 \\
\hline 0.4 & 60 & 0.343 & -200 & 5.523 & 68.64 & 0.657 & 1.339 \\
\hline 0.5 & 66 & 0.305 & -164 & 5.214 & 67.09 & 0.604 & 1.533 \\
\hline 0.6 & 72 & 0.274 & -140 & 4.962 & 65.80 & 0.559 & 1.727 \\
\hline 0.7 & 78 & 0.249 & -122.86 & 4.753 & 64.71 & 0.520 & 1.921 \\
\hline 0.8 & 84 & 0.228 & -110 & 4.577 & 63.77 & 0.487 & 2.115 \\
\hline 0.9 & 90 & 0.210 & -100 & 4.426 & 62.96 & 0.457 & 2.309 \\
\hline 1.0 & 96 & 0.195 & -92 & 4.296 & 62.25 & 0.431 & 2.503 \\
\hline 1.1 & 102 & 0.181 & -85.45 & 4.182 & 61.63 & 0.407 & 2.697 \\
\hline 1.15 & 105 & 0.175 & -82.61 & 4.130 & 61.34 & 0.396 & 2.794 \\
\hline 1.2 & 108 & 0.170 & -80 & 4.081 & 61.07 & 0.386 & 2.890 \\
\hline 1.3 & 114 & 0.159 & -75.38 & 3.993 & 60.57 & 0.367 & 3.084 \\
\hline 1.4 & 120 & 0.150 & -71.43 & 3.913 & 60.12 & 0.350 & 3.278 \\
\hline 1.5 & 126 & 0.142 & -68 & 3.842 & 59.72 & 0.334 & 3.472 \\
\hline
\end{tabular}

Note. $h=4 \mathrm{~mm} ; \alpha=20 \%$.

3.4. Negative Strip Distance. Negative strip distance is the displacement of mold moving downward relative to the slab during the negative strip time of an oscillation period. Then,
NSA (the area, shown in Figure 4) can be calculated as follows:

$$
\begin{aligned}
\mathrm{NSA} & =\int_{t_{1}}^{t_{2}}\left|v_{\mathrm{m}}-v_{\mathrm{c}}\right| \mathrm{d} t=2 \int_{(T / 2)-\left(T_{N} / 2\right)}^{T / 2}\left|v_{m}-v_{c}\right| \mathrm{d} t \\
& =2\left\{\int_{(T / 2)-\left(T_{N} / 2\right)}^{t_{D}}\left[2 k\left(t_{C}-t_{B}\right)\left(t-t_{C}\right)\right] \mathrm{d} t+\int_{t_{D}}^{T / 2}\left[v_{B}+2 k\left(t_{C}-t_{B}\right)\left(\frac{1}{2 f}+t_{B}-2 t_{C}\right)-k\left(t-\frac{1}{2 f}\right)^{2}\right] \mathrm{d} t\right\}-v_{c} t_{N} \\
& =2 k\left(t_{C}-t_{B}\right)\left(\frac{1}{2 f}+t_{B}-2 t_{C}\right)\left(\frac{1}{2 f}-t_{B}\right)-v_{c}\left(\frac{1}{2 f}-\frac{t_{N}}{2}-t_{C}\right)+\frac{4}{3} k\left(t_{C}-t_{B}\right)^{3}-v_{c} t_{N} \\
& =\frac{4 h(1-\alpha)^{2}}{\alpha^{2}+6 \alpha+1}+\frac{4 \alpha}{\alpha^{2}+4 \alpha+1}+\frac{v_{c}(\alpha-1)}{4 f}-\frac{v_{c} t_{N}}{2} .
\end{aligned}
$$

where NSA is the negative strip distance, $\mathrm{mm}$.

3.5. Positive Strip Time. Positive strip time $t_{p}$ is the time of the mold moving upward relative to the slab in an oscillating period. It can be determined as

$$
t_{p}=T-t_{N}=\frac{1}{f}-t_{N}=\frac{1+\alpha}{2 f}+\frac{v_{c}(1-\alpha)^{2}\left(\alpha^{2}+4 \alpha+1\right)}{24 h f^{2}(\alpha+1)^{2}} \text {. }
$$

where $t_{p}$ is the positive strip time, $s$.
3.6. Positive Strip Velocity. The positive strip velocity $\Delta v$ is the maximum velocity of mold moving upward relative to the slab. That is,

$$
\Delta v=\left|v_{u \max }\right|+\left|v_{c}\right|=\frac{6 f h(1+\alpha)}{\alpha^{2}+4 \alpha+1}+\left|v_{c}\right|,
$$

where $v_{u \max }$ is the maximum velocity of mold moving upward. A group of curves of positive strip velocity are illustrated in Figure 6 with different constants of $\Delta v$.

3.7. Curves for Multiparameters. Nonsinusoidal oscillation technological parameters of $t_{N}, N S, t_{p}$, and $\Delta v$ are illustrated in Figure 6. According to Figure 6, the values of these 
TABLE 3: Technological parameters of sinusoidal and nonsinusoidal oscillation.

\begin{tabular}{lcccccc}
\hline Oscillation mode & $v_{c}(\mathrm{~m} / \mathrm{min})$ & $f\left(\mathrm{~min}^{-1}\right)$ & $t_{N}(\mathrm{~s})$ & $N S A(\mathrm{~mm})$ & $t_{p}(\mathrm{~s})$ & $\Delta v(\mathrm{~m} / \mathrm{min})$ \\
\hline Sinusoidal & 1.15 & 104 & 0.205 & 3.259 & 0.372 & 3.764 \\
Nonsinusoidal & 1.15 & 105 & 0.175 & 4.130 & 0.396 & 2.794 \\
\hline
\end{tabular}

technological parameters can be taken into account simultaneously when the relationship between oscillation frequency and casting speed is determined. So by using multiparameter curves of oscillation shown in Figure 6, it is convenient to determine the synchrocontrol model of casting speed and oscillation frequency.

By using equations (6), (8), (12), and (13), a group of curves for negative strip time, negative strip ratio, positive strip time, and positive strip velocity are obtained with different values of $t_{N}$, NS, $t_{p}$, and $\Delta v$, which are shown in Figure 6. When NS equals $57.41 \%, t_{N}$ equals zero. If $N S$ is greater than or equal to $57.41 \%$, there will be no negative strip time which is not permitted for steel continuous casting production. If the oscillation parameters of $\alpha$ and $h$ changed, the multiparameter curves should be calculated again. According to the multiparameter curves, the synchrocontrolling model between casting speed and oscillation frequency determined can be suitable for different kinds of steel continuous casting.

The parameters of sinusoidal oscillation used in a steel plant are shown in Table1 [19].

To further enhance the slab surface quality, without changing oscillation amplitude of $4 \mathrm{~mm}$ and making modification ratio equal to $20 \%$, the synchrocontrol model of nonsinusoidal oscillation between casting speed and oscillation frequency is determined according to Figure 6 as follows:

$$
f= \begin{cases}60, & v_{c}<0.4, \\ 60 \cdot v_{c}+36, & v_{c} \geq 0.4 .\end{cases}
$$

Using the relationship of equation (14), the nonsinusoidal oscillation technological parameters are calculated and illustrated in Table 2.

The comparison of technological parameters between sinusoidal oscillation and nonsinusoidal oscillation is illustrated in Table 3. From Table 3, it can be found that under the same casting speed, the negative strip time and the positive strip velocity of the nonsinusoidal oscillation are smaller than those of sinusoidal oscillation, which would make the depth of the oscillation marks shallower and the tensile friction on the slab reduce. The negative strip distance of the nonsinusoidal oscillation is larger than that of sinusoidal oscillation, which is helpful to remove the slab from mold, weld the cracks in a solidified shell together, and increase casting speed. The positive strip time of nonsinusoidal oscillation is longer than that of sinusoidal oscillation, which will lead to a better lubrication condition with a larger quantity of casting powder consumption, reduce the tensile stress, and minimize cracks of solid shell. Thus, nonsinusoidal oscillation is superior to sinusoidal oscillation for improving surface quality of slab and decreasing the probability of steel breakout.

\section{Conclusions}

A nonsinusoidal oscillation waveform proposed could control the maximum acceleration, which has good dynamic characteristics due to the continuity of velocity and acceleration. By selecting reasonable basic oscillation parameters and the synchrocontrol model, it could satisfy the continuous casting production of different kinds of steel. The synchrocontrol model of oscillation frequency and casting speed proposed is reasonable and could gain better technological oscillation parameters. Compared with sinusoidal oscillation, the nonsinusoidal oscillation is beneficial to improve the surface quality of the slab and enhance casting speed. In the future, the nonsinusoidal oscillation waveform can be realized by different oscillators, which can reduce the inertia force and prolong the service life of the equipment.

\section{Data Availability}

No data were used to support this study.

\section{Conflicts of Interest}

The authors declare that there are no conflicts of interest.

\section{Acknowledgments}

This work was financially supported by the National Natural Science Foundation of Hebei Province of China (E2016203492 and E2018203062). This work was also supported by the National Natural Science Foundation of China (51275446 and 61503323), and Hebei Provincial project for Returned overseas personnel (C2013005012).

\section{References}

[1] X.-Z. Zhang, X.-R. Zheng, Q.-G. Liu, X.-K. Li, and Y.-M. Fang, "Investigation and application of non-sinusoidal oscillation technique of mold," Journal of Iron and Steel Research International, vol. 20, no. 12, pp. 19-24, 2013.

[2] C. Zhou, X.-Z. Zhang, F. Wang, P.-F. Liu, and Y.-M. Fang, "Mechanism analysis of non-sinusoidal oscillation of continuous casting mold synchronously driven by double servomotors," Journal of Iron and Steel Research International, vol. 24, no. 3, pp. 251-257, 2017.

[3] H. B. Wang, B. Su, Y. L. Wang, and J. Gao, "Adaptive sliding mode fixed-time tracking control based on fixed-time sliding mode disturbance observer with dead-zone input," Complexity, vol. 2019, Article ID 8951382, 14 pages, 2019.

[4] G. P. Kang, G. Shin, and C. G. Kang, "Development of new model of mold oscillator in continuous casting," Journal of Mechanical Science and Technology, vol. 21, no. 3, pp. 421-425, 2007.

[5] X.-B. Zhang, W. Chen, and L.-F. Zhang, "A coupled model on fluid flow, heat transfer and solidification in continuous 
casting mold," China Foundry, vol. 14, no. 5, pp. 416-420, 2017.

[6] X. Meng and M. Zhu, "Optimisation of non-sinusoidal oscillation parameters for slab continuous casting mould with high casting speed," Ironmaking \& Steelmaking, vol. 36, no. 4, pp. 300-310, 2013.

[7] G. Q. Lin, P. Tang, F. J. Kong, X. Qi, J. G. Wang, and G. H. Wen, "Study on optimizing parameters of mold oscillation of billet caster at Nanjing steel," Iron and Steel, vol. 40, no. 6, pp. 27-29, 2005.

[8] C. X. Wang, X. H. Wang, W. J. Wang, and L. Zhang, "Quality improvement of cc slabs by increasing mold oscillation frequency and reducing amplitude," Iron and Steel, vol. 38, no. 1, pp. 19-21, 2003.

[9] Y. Yao, J. Li, and Y. Fang, "Motion stability analysis of nonsinusoidal oscillation of mold driven by servomotor," Chinese Journal of Mechanical Engineering, vol. 28, no. 6, pp. 12691276, 2015.

[10] M. Suzuki, H. Mizukami, T. Kitagawa, K. Kawakami, S. Uchida, and Y. Komatsu, "Development of a new mold oscillation mode for high-speed continuous casting of steel slabs," ISIJ International, vol. 31, no. 3, pp. 254-261, 1991.

[11] X. Zhang, X. K. Li, X. R. Zheng et al., "Study of non-sinusoidal oscillation of mold driven by ellipse gears," Chinese Journal of Mechanical Engineering, vol. 40, no. 11, pp. 178-181, 2004.

[12] X. Z. Zhang, C. Zhou, P. F. Liu, and J. Guan, "Investigation of waveform and technological parameters for non-sinusoidal oscillation of mold driven by double eccentric shafts," China Mechanical Engineering, vol. 27, no. 23, pp. 3125-3129, 2016.

[13] X. Z. Zhang, H. T. Zhu, A. K. Tieu et al., "An investigation of mechanical non-sinusoidal oscillation of continuous casting mold," Advanced Materials Research, vol. 264-265, pp. 337342, 2011.

[14] D. W. Liu, L. M. Luo, G. H. Wang, and X. Jin, "Integrated design of non-sinusoidal generator of continuous casting mold," China Mechanical Engineering, vol. 28, no. 21, pp. 2608-2613, 2017.

[15] Q. H. Hong and D. C. Hu, "Research for the non-sinusoidal oscillation wave based on the Fourier series," Heavy Machinery, vol. 3, pp. 15-19, 2008.

[16] C. W. Ma, "Some discussion about several non-sinusoidal oscillation waveforms of mold," Continuous Casting, vol. 1, pp. 22-28, 2014.

[17] X. N. Meng and M. Y. Zhu, "Non-sinusoidal oscillation waveform conformation and parametrical research for continuous casting mold," China Mechanical Engineering, vol. 18, no. 15, pp. 1779-1782, 2007.

[18] X. Li, X. M. Wu, Y. M. Fang, Z. Q. Xu, X. R. Zheng, and D. M. Zhang, "Method to construct waviness function of mold non-sinusoidal oscillation," Chinese Journal of Mechanical Engineering, vol. 36, no. 1, pp. 67-70, 2000.

[19] C. Zhou, X. Z. Zhang, F. Wang, Y. M. Fang, and S. B. Ren, "Investigation of non-sinusoidal oscillator of continuous casting mold synchronously driven by double servomotors and technological parameters," Journal of the Chinese Society of Mechanical Engineers, vol. 40, no. 1, pp. 33-40, 2019. 